\title{
Diagnostic Value of Lung Ultrasonography in Children with COVID-19
}

\author{
Mina Gharibzadeh Hizal ${ }^{1}$, Kubra Aykac ${ }^{2}$, Burcu Ceylan Cura Yayla ${ }^{3}$, Arzu Yılmaz ${ }^{2}$, \\ Gulsum Iclal Bayhan ${ }^{4}$, Demey Altun ${ }^{5}$, Habibp Eser Akkaya ${ }^{2}$, Aysegul Nese Citak Kurt ${ }^{6}$, \\ Jale Karakaya $^{1}$, Yasemin Ozsurekci ${ }^{7}$, and Mehmet Ceyhan ${ }^{8}$ \\ ${ }^{1}$ Hacettepe University \\ ${ }^{2}$ Sağlık Bakanlı̆̆ 1 Ankara Ĕ̆itim ve Araştırma Hastanesi \\ ${ }^{3}$ Saglik Bakanligi Ankara Egitim ve Arastirma Hastanesi \\ ${ }^{4}$ Yildirim Beyazit University Faculty of Medicine \\ ${ }^{5}$ Ufuk University \\ ${ }^{6}$ Yildirim Beyazit University \\ ${ }^{7}$ Hacettepe University Faculty of Medicine \\ ${ }^{8}$ Hacettepe University, Faculty of Medicine,
}

June 27, 2020

\begin{abstract}
Background: Lung ultrasound (LUS) has been successfully used in the diagnosis of different pulmonary diseases. Present study design to determine the diagnostic value of LUS in the evaluation of children with COVID-19, and to compare chest X-ray and LUS results with tomography (CT). Method and objectives: In this prospective multi-center study, 40 children with confirmed COVID-19 were included. LUS was performed to all patients at admission. The chest X-ray and CT were performed according to the decision of the primary physicians. LUS results were compared with chest X-ray and CT. The sensitivity and specificity and diagnostic performance was determined. Results: Of the 40 children median (range) was 10.5 (0.4-17.8) years. Chest X-ray and LUS were performed on all and chest CT was performed on $28(70 \%)$ patients at the time of diagnosis. Sixteen (40\%) patients had no apparent chest CT abnormalities suggestive of COVID-19, whereas 12 (30\%) had abnormalities. LUS confirmed the diagnosis of pulmonary involvement in 10 out of 12 patients with positive CT findings. LUS demonstrated normal lung patterns among 15 patients out of 16 who had normal CT features. The sensitivity identified by the chest X-ray and LUS tests was comparedand statistically significantly different $(\mathrm{p}=0.016)$. Chest X-ray displayed false-negative results for pulmonary involvement in $75 \%$ whereas for LUS it was $16.7 \%$. Conclusions: LUS might be a useful tool in the diagnostic steps of children with COVID-19. A reduction in chest CT assessments may be possible when LUS is used in the initial diagnostic steps for these children.
\end{abstract}

\section{Hosted file}

Manuscript COVID Pediatric pulmonology.doc available at https://authorea.com/users/337441/ articles/463040-diagnostic-value-of-lung-ultrasonography-in-children-with-covid-19 

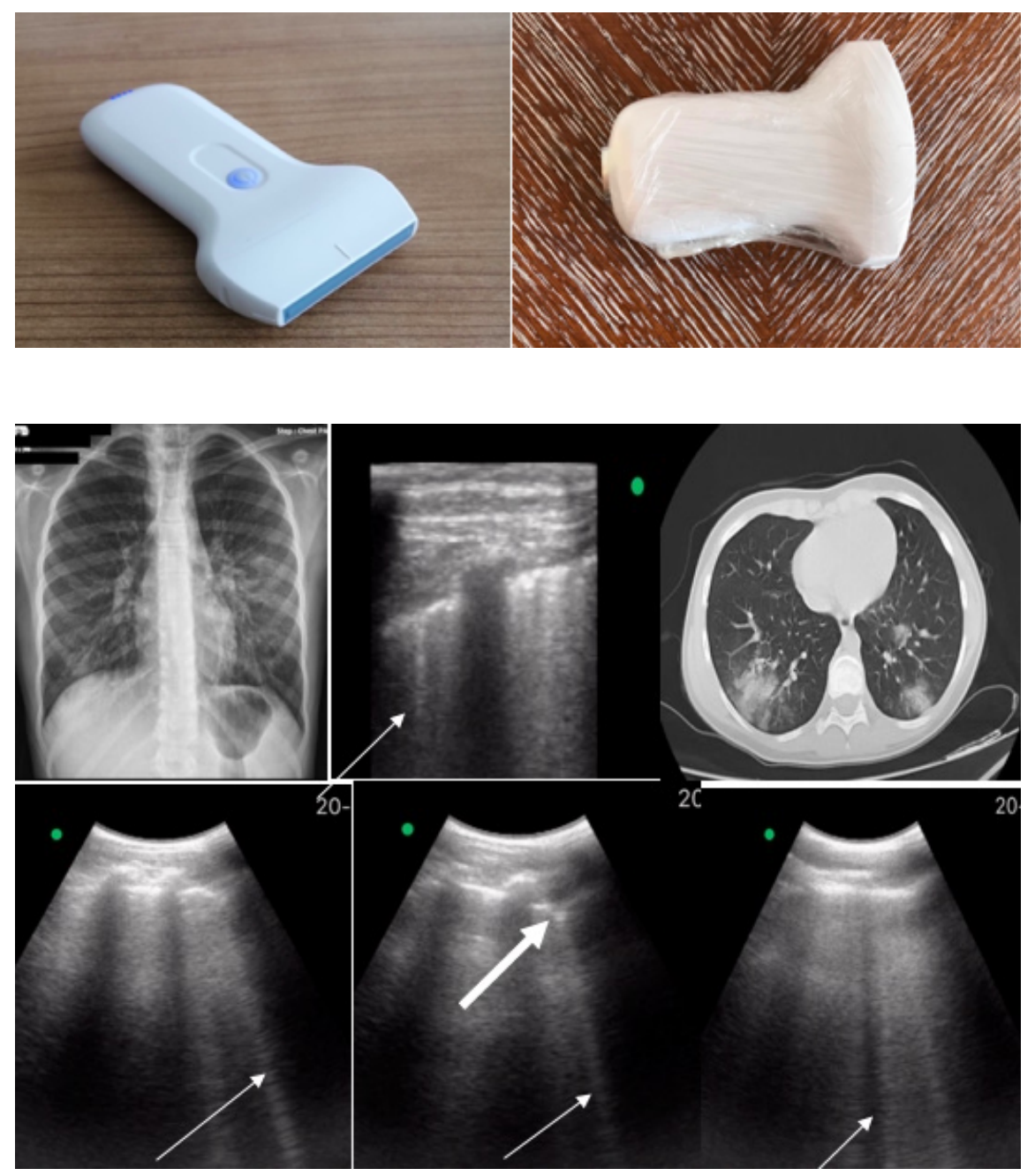


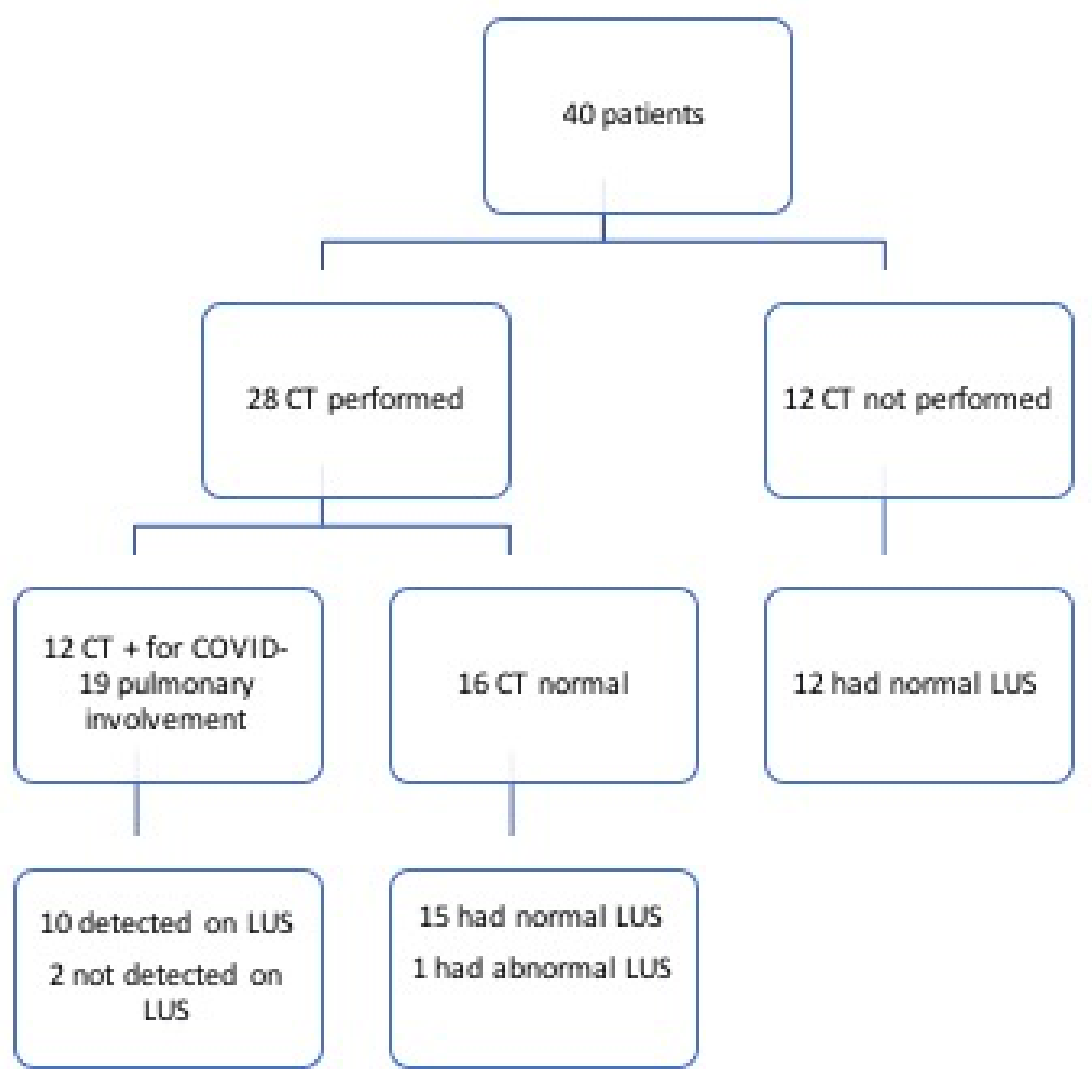

